\title{
Development and Evaluation of Biodegradable Polymeric Based Long Acting in situ Forming Microparticles of LHRH Agonist Goserelin Acetate
}

\author{
Velenti Chauhan, Vimal Patel, Bhavesh Akbari, Rohan Barse \\ Department of Pharmaceutics, Shree Dhanvantary Pharmacy College, Kim, Surat, Gujarat, INDIA.
}

\begin{abstract}
Aim: Goserelin acetate is parenterally administered, a typical LHRH analogue for the treatment of prostate cancer. The objective of present work was to formulate and evaluate long acting in situ forming microparticles of goserelin using PLGA which would extend the drug release. Materials and Methods: PLGA 50:50 were used as the biodegradable polymer, DMSO was as organic solvent and sesame oil was used as dispersion phase. HLB based system was used in present investigation for stabilizing non-aqueous emulsion prior to administration. Emulsifier mixtures of Span 80 and Tween 80 in different combination were prepared to stabilize microemulsion system with required HLB of external oil. Result: Developed microsphere batch E06 was found to be more stable with external phase ratio 2:8 were visualized under an inverted biological microscope. In vitro drug release profile of goserelin acetate was investigated that ISMs were minimized burst effect and release up to 24 days and it was found to be stable after 1 month. The drug release was observed $95.97 \%, 94.02 \%$ and $97.77 \%$ after 24 days in the batches A, B and C respectively of emulsion E06. Conclusion: ISMs of goserelin were successfully formulated and could be a potential substitute for a marketed formulation. The developed Biodegradable injectable in-situ microparticles (ISMs) were found to be optimized, formed stable, spherical and non- porous formulation.
\end{abstract}

Key words: Goserelin acetate, In-situ forming microparticles, PLGA, HLB, Burst effect.

\section{INTRODUCTION}

Prostate cancer is a cancer of the small walnut-shaped gland in males that produces seminal fluid, the fluid that nourishes and transports sperm. ${ }^{1,2}$ Androgen deprivation therapy (ADT) or Androgen suppression therapy (AST) has been used for the management of advanced prostate cancer for more than 30 years. Specific androgen suppression using synthetic analogues, referred to as Luteinising hormone releasing hormone (LHRH) agonist, have become the standard of care for the prostate cancer. Long acting synthetic LHRH agonist analogues currently available include leuprolide, goserelin, triptorelin and buserelin administered as either intramuscular or subcutaneous depot injections on a 1,2, 3 or 6-month basis. Injectable in situ forming drug delivery systems having being increased advertence as an alternative to surgical implants and microspheres, due to ease of fabrication. They can be classified based on their implant formation mechanism like in situ cross linked implants, solidify organogels, phase separation systems and in situ precipitation. Poly (lactide/glycolide) based in situ forming systems are (A) in situ forming implants (ISI), (B) in situ forming microparticles (ISM). ${ }^{3,4}$ Jain et al. was developing a novel in situ method for the preparation of injectable stable dispersion of PLGA micro globules (premicrospheres or embryonic microspheres). The preparation made up of two oil phases. The oil phase I consists of a mixture of PLGA/ triacetin/ drug/PEG 400/tween 80. This mixture is
Submission Date: 09-07-2018; Revision Date: 14-08-2018; Accepted Date: 29-12-2018

DOI: 10.5530/ijper.53.2.29 Correspondence: Dr. Bhavesh Akbari, Department of Pharmaceutics, Shree Dhanvantary Pharmacy College, Kim Surat, Gujarat, INDIA.

Phone: +919979983654 E-mail: bhaveshakbari83@ gmail.com

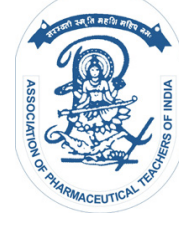

www.ijper.org 
added drop wise to oil phase II which composed of miglyol 812 and span 80 and homogenized to produce rubbery injectable dispersion of PLGA micro globules. The produced embryonic or pre-microspheres harden, shrink, were able to entrapping the drug and form true microspheres in situ within 17 min. ${ }^{5}$ Deadman et al. studied the effect of drug lipophilicity on its release profile from different controlled release vehicles such as, PLGA micro particles and in situ forming depots. They reported that, although there was minor effect of drug lipophilicity on the in vitro studies that effect was obvious in vivo which attributed to the interactions between the formulation and the biological tissue. Moreover, recent developments in this field such as the first Phase I trial of Risperidone-ISM ${ }^{\mathrm{TM}}$ suggest there is a possibility for prolonged release of bioactive molecules applied as intramuscular injection. ${ }^{6}$ In order to minimize burst release by decreased a viscosity of the system; a novel approach has been developed. The drug incorporating organic polymeric inner phase was emulsified with an oily external continuous phase containing oil soluble stabilizer. Micro droplets of an inner phase solidify after contact with physiological fluid to form solid in situ forming microparticles (ISM). ${ }^{7}$ An advantage of such formulation is that a lower viscosity as compare to ISI formulation, due to viscosity is assigned by the continuous phase. It has less painful and lower concentration of polymer can be used, additionally is showed reduced burst effect and lower mytoxicity as compared to ISI. Another advantages of it is the regular spherical shaped of microparticles, which is determined by the size of the previous droplets in emulsion and thereby minimize the morphological variations that provides more consistence and reproducible release pattern than ISI. Although for emulsion system, the malice use of emulsifier is main drawback could be lack knowledge of emulsion stability. In case of injection, ISM is prepared prior to administration does not make challenges itself. However, the coalescence of droplets could occur during their solidification. Burst reduction depending on the type of polymer and solvent used, increasing polymer concentration and decreasing drug loading. Higher viscosity of external oil phase, faster emulsification rate and internal: external phase ratio can also contribute to burst reduction. ${ }^{8,9}$

\section{MATERIALS AND METHODS}

\section{Materials}

Goserelin Acetate was procured from Carbosynth Ltd, Berkshire, UK. PLGA (50:50) was obtained as a gift sample from Evonik, Mumbai, India. All other chemicals and reagents used were of Research grade.

\section{Methods \\ Drug characterization and Identification}

Drug characterization was done by UV spectroscopy and Identification of Goserelin Acetate was carried out using FTIR study. For this the FTIR spectra of plain drug was recorded in FTIR- 8400 S Shimadzu spectrophotometer. The pure Goserelin Acetate drug was mixed with thoroughly with potassium bromide. Then the scans were obtained at a resolution of $4000-400 \mathrm{~cm}^{-1}{ }^{10}$

\section{Drug polymer compatibility study}

Chemical Compatibility of Goserelin Acetate with PLGA polymer was determined by FTIR study. Physical compatibility of Goserelin Acetate, polymer and physical mixture of drug and polymer were carried out using a Differential scanning calorimetry (DSC). The temperature ranges used for heating all the samples was $50-300^{\circ} \mathrm{C} .{ }^{10}$

\section{Solubility and miscibility of polymer and drug in solvents and water}

In order to determine the solubility, Goserelin Acetate 5 $\mathrm{mg}$ was added in $1 \mathrm{ml}$ of water, $1 \mathrm{ml}$ of solvent DMSO and $1 \mathrm{ml}$ of polymer solution were incubated at $37^{\circ} \mathrm{C}$ overnight. Solubility was determined by visual inspection. Solubility of PLGA (50:50) in solvent; $200 \mathrm{mg}$ of PLGA was added in $1 \mathrm{ml}$ of solvent DMSO was stirred on magnetic stirrer for $1 \mathrm{~h}$ and then incubated at $37^{\circ} \mathrm{C}$ overnight. Solubility was determined by visual inspection. Miscibility of solvent and polymeric solution in water (dissolution medium), $1 \mathrm{ml}$ of solvent DMSO and $1 \mathrm{ml}$ of polymer solution containing $200 \mathrm{mg}$ PLGA in DMSO were added in $1 \mathrm{ml}$ of water and their miscibility was observed by visual inspection.

\section{Preparation of ISM forming Non- aqueous injectable emulsion}

First was prepared drug polymeric solution by dissolving $100 \mathrm{mg}$ PLGA in $0.2 \mathrm{ml}$ DMSO on hot plate and allow cooling down at room temperature. Then add $10 \mathrm{mg}$ of drug in a polymeric solution and sterilized by membrane filtration. External oil phase was prepared by calculated amount of emulsifier mixture required to achieve desire HLB value of oil were added in a $0.8 \mathrm{ml}$ in oil phase, both phases were filled in syringe and homogenized by hand shaking prior to administration.,11

\section{Optimization of stable non- aqueous emulsion}

Development and optimization of stable non- aqueous emulsion system based on HLB values of oils. Firstly selection of external oil phase based on HLB value. For 
Table 1: Percentage of emulsifier mixture required for particular HLB.

\begin{tabular}{|c|c|c|}
\hline \multirow{2}{*}{ Require HLB } & \multicolumn{2}{|c|}{ \% of Emulsifier required } \\
\cline { 2 - 3 } & \% Span-80 & \% Tween-80 \\
\hline 5.4 & 90 & 10 \\
\hline 7 & 75 & 25 \\
\hline 9 & 57 & 43 \\
\hline 10 & 45 & 55 \\
\hline 11 & 37 & 63 \\
\hline 12 & 28 & 72 \\
\hline 15 & - & $100^{*}$ \\
\hline
\end{tabular}

[* indicate the amount of tween 80 in $100 \%$ ]

that we selected 3 different bio-edible oils had distinct HLB value such as castor oil, corn oil and sesame oil having HLB value 14, 10 and 7 respectively, but the castor oil have been rejected due to higher viscosity.

Further was selected of suitable emulsifier mixture based on their solubility in water and bio-edible oil. The Span 80 with HLB 4.3 has more soluble in oil as compared to different span derivative and the Tween 80 with HLB 14 had chosen due to higher solubility in water. Allegation method was performed to determine percentage of emulsifier mixture required to stabilize emulsion with different HLB value of oils. Table 1 showed the percentages of emulsifier were required to stabilize.

Finally concentration of emulsifier mixture required to stabilize the emulsion were calculated. We prepared emulsion containing $10 \%, 15 \%, 20 \%$ and $30 \%$ emulsifier mixture produce less phase separated formulation descript in Table 2.

There were 8 test tubes in which first 4 were corn oil emulsion and next 4 were sesame oil emulsions containing
$10 \%, 15 \%, 20 \%$ and $30 \%$ emulsifier respectively. Further 30 min its showed that emulsion E06 is more stable than any other emulsion and no phase separation occurred, continuous observation till $6 \mathrm{hr}$ remain stable emulsion. It's was also indicate that the phase separation is increase with respect to the emulsifier concentration. Finally the conclusion was drawn that is sesame oil formed more stable emulsions as compared to corn oil. The emulsion E06 was selected as best formulation which has been fulfill the requirement of injectable emulsion.

\section{Evaluation of Non- Aqueous Injectable Emulsion} FT-IR studies

Chemical compatibility of Goserelin Acetate with PLGA and DMSO were analyzed by FT-IR. Any changes in the chemical position or changes in functional groups characteristics peak of drug in IR spectra after combining with excipients were investigated.

\section{DSC analysis}

Compatibility of Goserelin Acetate and PLGA in physical mixture was analyzed by DSC thermo gram analysis. Any changes in thermo gram peaks of drug in physical mixture after combining with polymer were investigated. ${ }^{12}$

\section{$\mathrm{pH}$}

The $\mathrm{pH}$ of the polymeric droplet emulsion was tested using digital $\mathrm{pH}$ meter.

\section{Syringeability and Injectability}

Injectability in general means the injection into the desirable site of administration. Syringeability is defined as the ease of withdrawal of a product through a needle from the container. Sample $(1 \mathrm{ml})$ was filled into $5 \mathrm{ml}$ syringe with attached 18 gauge needle. The syringe was connected to rubber tube ended with air pump. ${ }^{13}$

\begin{tabular}{|c|c|c|c|c|c|}
\hline \multirow{2}{*}{$\begin{array}{l}\text { Formulation } \\
\text { code }\end{array}$} & \multirow{2}{*}{$\begin{array}{c}\text { Internal phase } \\
\text { concentration } \\
(\% \mathrm{v} / \mathrm{v})\end{array}$} & \multirow{2}{*}{$\begin{array}{c}\text { External phase } \\
\text { concentration } \\
(\% \mathrm{v} / \mathrm{v})\end{array}$} & \multicolumn{3}{|c|}{$\begin{array}{c}\text { Emulsifier concentration (\%v/v with respect to } \\
\text { external phase) }\end{array}$} \\
\hline & & & $\begin{array}{l}\text { Emulsifier } \\
\text { mixture }\end{array}$ & Span 80 & Tween 80 \\
\hline \multicolumn{6}{|c|}{ Corn oil emulsions with HLB 10} \\
\hline E01 & \multirow{4}{*}{$20 \%$} & \multirow{4}{*}{$80 \%$} & $10 \%$ & \multirow{4}{*}{$45 \%$} & \multirow{4}{*}{$55 \%$} \\
\hline E02 & & & $15 \%$ & & \\
\hline E03 & & & $20 \%$ & & \\
\hline E04 & & & $30 \%$ & & \\
\hline \multicolumn{6}{|c|}{ Sesame oil emulsions with HLB 7} \\
\hline E05 & \multirow{4}{*}{$20 \%$} & \multirow{4}{*}{$80 \%$} & $10 \%$ & \multirow{4}{*}{$75 \%$} & \multirow{4}{*}{$25 \%$} \\
\hline E06 & & & $15 \%$ & & \\
\hline E07 & & & $20 \%$ & & \\
\hline E08 & & & $30 \%$ & & \\
\hline
\end{tabular}




\section{In vitro formation of microparticles}

In order to investigate microparticles were formed in vitro from non- aqueous emulsion, final formulation was injected into $50 \mathrm{ml}$ phosphate buffer $\mathrm{pH} 7.4$ and $0.02 \%$ sodium azide, incubated for $24 \mathrm{hr}$ at $37^{\circ} \mathrm{C}$. Then microparticles were visualized with an inverted biological microscope until complete hardening of microparticles observed..$^{13}$

\section{Ex- vivo formation of microparticles}

In order to confirm that the microparticles formed in the human tissues, ex-vivo study was performed. Isolated chicken leg muscles were used for this study. The formulation was mixed with methylene blue dye which locates the microparticle formation in the muscle. The formulation was injected to a depth of $0.5 \mathrm{ml}$ using an 18 gauge marked needle. The muscle was immersed in $25 \mathrm{ml}$ of phosphate buffer $\mathrm{pH} 7.4$ and kept for $24 \mathrm{hr}$ at $37^{\circ} \mathrm{C}$. The confirmation of microparticles formation was observed under inverted biological microscope in the muscle after injection of formulation. ${ }^{14}$

\section{In vitro drug release study}

The novel polymeric emulsion was injected using syringe attached with 18 gauge needles followed by the addition of $1 \mathrm{ml}$ of the release medium into pieces of dialysis tubing tied at one end. The other end of the sacs was tied with threads and the sacs were placed into a vial containing $10 \mathrm{ml}$ of phosphate buffer $\mathrm{pH} 7.4$ containing $0.02 \% \mathrm{w} / \mathrm{v}$ sodium azide. The vial was placed in a reciprocating incubator shaker maintained at $37^{\circ} \mathrm{C}$. With an oscillation speed of $50 \mathrm{rpm}$. At different sampling points the release medium was removed from the vial and replace with fresh medium. The amount of drug release into the medium was determined by UV spectroscopy. The actual amount of the polymer- drug solution incorporated in the final formulation was taken as basis for the drug release and encapsulation efficiency. ${ }^{14}$

\section{Terminal sterilization}

The preparation of drug containing polymeric internal phase was carried out aseptically including sterilization. Terminal sterilization of polymeric solution was finalized by filter membrane with $2 \mu$ pore size. ${ }^{15}$

\section{Drug Release kinetic models}

The release kinetic of injectable in situ microparticle forming system was carried out. The release data were tested for the Zero order, First order, Higuchi, HixsonCrowell and Korsmeyer- Peppas equation. ${ }^{16}$

\section{Stability studies}

The internal polymeric phase was subjected to stability study for a period of 1 month at storage condition of $4^{\circ} \mathrm{C}$. Appearance, $\mathrm{pH}$, syringeability and drug content at different interval of one week during one month. ${ }^{17}$

\section{RESULTS AND DISCUSSION \\ Drug characterization}

FT-IR spectra of Goserelin Acetate was showed prominent peak at $1099.46 \mathrm{~cm}^{-1}$ lying in the range characteristics for 1250-1020 $\mathrm{cm}^{-1}$ for $\mathrm{C}-\mathrm{N}$ bonds. It showed other peak at $1653.35 \mathrm{~cm}^{-1}$ which indicate the $\mathrm{C}=\mathrm{O}$ bonds. While peaks at $3417.96 \mathrm{~cm}^{-1}$ and $2927.08 \mathrm{~cm}^{-1}$ indicates hydroxyl and $\mathrm{C}-\mathrm{H}$ stretching in Goserelin Acetate. Thus, from the obtained peak it can be concluded that the given sample of drug Goserelin Acetate. (Figure 1 (a) and Figure 1(b)). The UV spectroscopic analysis of Goserelin Acetate the Absorbance maxima wavelength was found at $278 \mathrm{~nm}$ which was reported value for major peptides. Hence, $278 \mathrm{~nm}$ was selected as a maximum wavelength. The calibration curve was taken in Phosphate buffer $\mathrm{pH} 7.4$ within wide range of drug concentration about $20-50 \mu \mathrm{g} / \mathrm{ml}$. The calibration curve showed a linear relationship with a regression coefficient $\left(\mathrm{R}^{2}\right)$ of 0.994 . The absorbance was found to lie within the range of Beer and Lambert law.

\section{Polymer characterization by FT-IR}

FT-IR spectra of distinct functional groups of PLGA polymer exhibits molecular vibration as illustrated in Figure 2(a). The peak at $2931.90 \mathrm{~cm}^{-1}$ falling within range $3010-2885 \mathrm{~cm}^{-1}$ is attributed to $\mathrm{C}-\mathrm{H}$ stretching. Intense band observed at $1749.49 \mathrm{~cm}^{-1}$ in the range region between $1760-1750 \mathrm{~cm}^{-1}$, are attributed to the stretching vibration of the $\mathrm{C}=\mathrm{O}$ groups present in the monomers. Medium intensity bands at $1094.54 \mathrm{~cm}^{-1}$ between $1300-1000 \mathrm{~cm}^{-1}$ were attributed to asymmetric $\mathrm{C}-\mathrm{C}(=\mathrm{O})-\mathrm{O}$ stretches. A narrow peak at $1392.65 \mathrm{~cm}^{-1}$

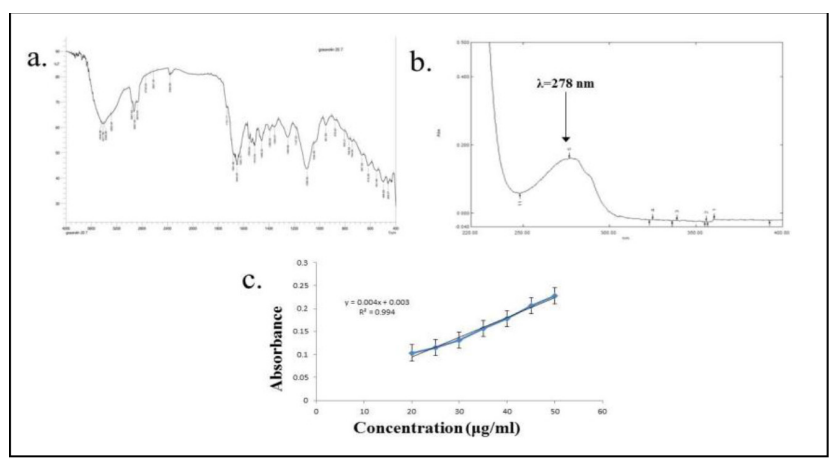

Figure 1: Drug characterization. 


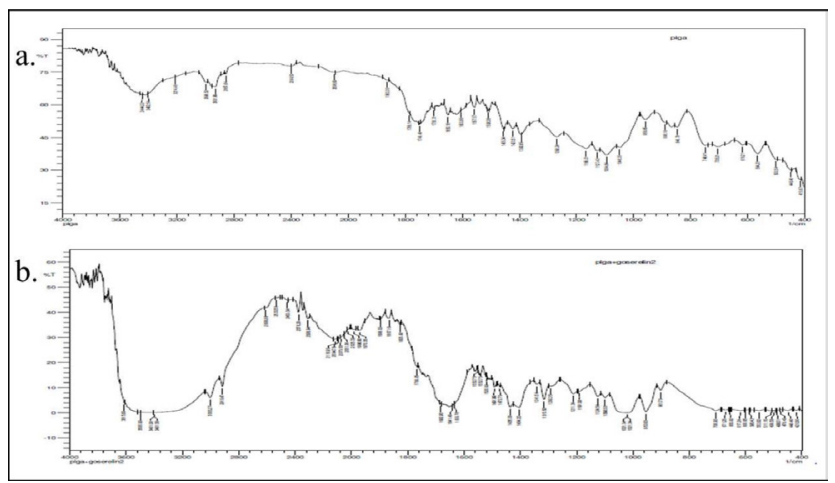

Figure 2: FT-IRs (a) Plain PLGA (50:50) polymer and (b) In-situ forming microparticles.

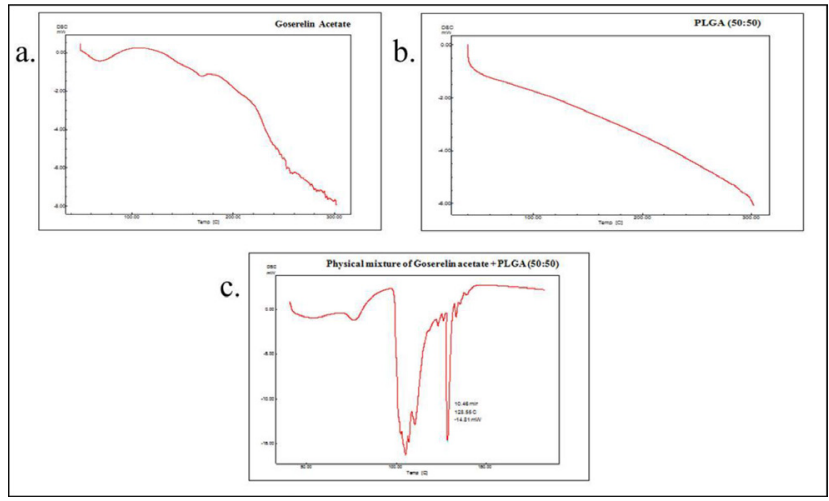

Figure 3: DSC thermograms (a) Goserelin Acetate, (b) PLGA (50:50) and (c) Physical mixture of Goserelin Acetate.

in the region between $1450-850 \mathrm{~cm}^{-1}$ is attributed to $\mathrm{C}-\mathrm{H}$ bonding. It was observed that the FT-IR peaks of PLGA are nearly equal to the peaks reported, therefore it can be concluded that polymer is PLGA.

\section{Drug Excipient compatibility study}

FT-IR spectra of the formulation in Figure 2 (b) depict all the entire prominent peak of present drug. There was no marked shift in the major peaks of drug in the physical mixture of drug and polymer. So it was concluded that drug was stable in the physical mixture. It also indicates that the drug did not interact chemically with the polymer.

\section{DSC analysis of formulation}

The DSC thermo gram of both Goserelin acetate and PLGA illustrated in Figure 3 (a) and 3 (b) It was showed no thermal peak, which indicates that drug and polymer both are in amorphous form. Figure 3(c) showed two thermal peaks which does not indicates the re- crystallization of either drug or polymer. Thus it can be concluded that drug and polymer were found to be compatible with each other in physical mixture.
Solubility and miscibility of polymer and drug in solvent and water

Goserelin acetate knowingly freely water soluble peptide drug. From the solubility studies it predicted that the drug was soluble in solvent as well as in polymer solution to form homogenous system with good syringe ability. The PLGA (50:50) was found to be soluble in DMSO and provides clear transparent polymeric solution. DMSO is polar aprotic solvent miscible with wide ranges of organic solvent and water. PLGA is synthetic biodegradable polymer, hydrolytically unstable and insoluble in water, but when added polymeric solution in water, liquid- liquid de-mixing lead to phase separation causes precipitation of PLGA form homogenous dispersion.

\section{Evaluation of ISM forming Non- Aqueous injectable emulsion}

\section{$\mathrm{pH}$, appearance and syringe ability}

The $\mathrm{pH}$ of injectable emulsion was found to be 7.36 which suitable for subcutaneous injection, $\mathrm{pH}$ was found within the range of body fluid $\mathrm{pH}$. Colour of emulsion comprising of sesame oil gave yellowish dark emulsion, after homogenization it has been easily withdrawal from vials, as it has no particulate that would hinder the syringe ability.

\section{In vitro formation of microparticles}

Emulsion was then injected in beaker containing $50 \mathrm{ml}$ phosphate buffer $\mathrm{pH} 7.4$ and $0.02 \% \mathrm{w} / \mathrm{v}$ sodium azide. The microparticles were formed slowly in a buffer medium after leaching of solvent from oil globules. The hardening of microparticles in slow rate observed under inverted biological microscope. Figure 4 showed the microparticles were visualized with an inverted biological microscope until complete hardening of globules.

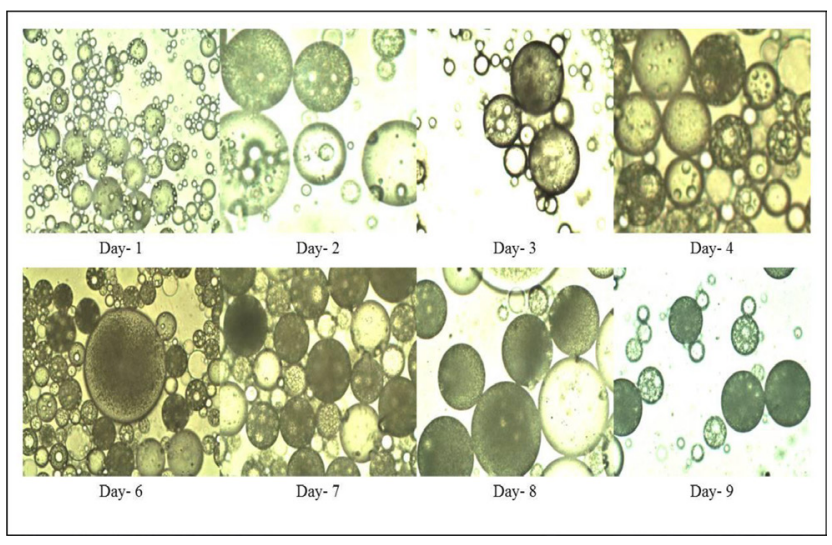

Figure 4: ISMs observed under inverted biological microscope for 9 days. 


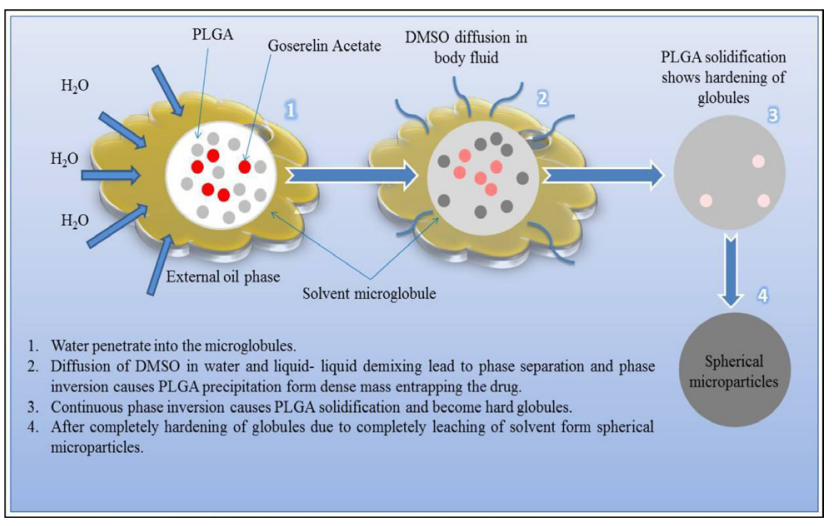

Figure 5: Slow rate diffusion and phase inversion of PLGA.

\section{Slow diffusion phase inversion dynamics}

After injection of emulsion upon contact with buffer media (in-vitro) and body fluid (in-vivo), the polymer system undergoes slow rate diffusion and phase separation due to presence of external oil phase. The rate of solvent diffusion is much more controlled thereby preventing sudden polymer precipitation at any point. Depot can be stay more or less viscous during time of prolonged solidification, produced less porous sponge like hardening structure are more homogenous. Drugs got entrapped within the matrix as it solidifies and was released by diffusion processes or as the implant biodegrades. Drug diffusivity was decreased as well as diffusion path length increased result a more gradual release pattern of drug. Figure 5 was showed the mechanism behind formation of ISM in water or body fluid by slow rate diffusion and phase separation of polymer. ${ }^{13}$

\section{Ex- vivo formation microparticles}

It was confirmed under inverted biological microscope that developed microparticles were formed slowly in buffer medium after leaching of solvent from oil globules (Figure 6).

Ex-vivo study was carried out confirm formation of in situ microparticles in the muscles. The crystal violet dye added in the formulation differentiated the microparticles formation in the muscles. After injection of emulsion containing dye present in polymeric phase, the muscles sacs were appeared blue color which indicated formation of microparticles. Figure 7. the digital microscopy of transverse section of leg tissues after $24 \mathrm{hr}$ was shows microparticles generated in tissues.

\section{$\%$ In vitro drug release study}

In vitro drug release study of emulsion E06 was carried out in three different batches A, B and C. Figure 8. Showed comparative drug release profile for batches A, $\mathrm{B}$ and $\mathrm{C}$. The drug release was observed for all batches

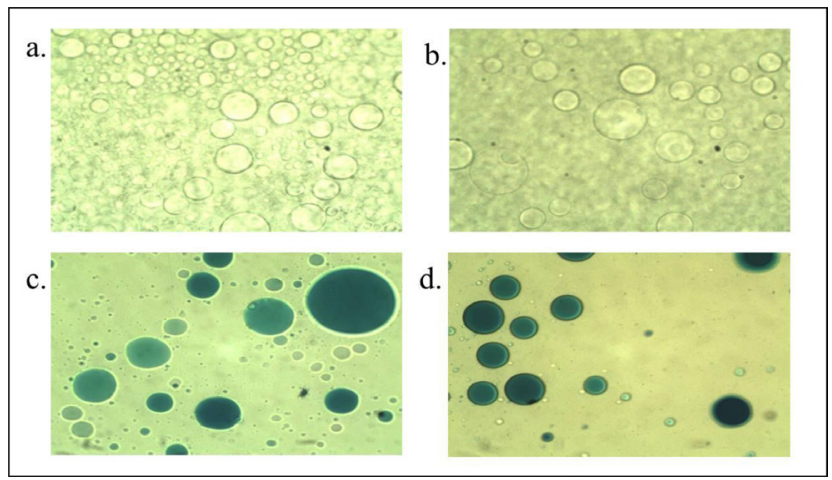

Figure 6: $(a, b)$ emulsion containing drug loaded polymeric droplets and (c, d) emulsion containing dye loaded polymeric droplets observed under biological microscope.

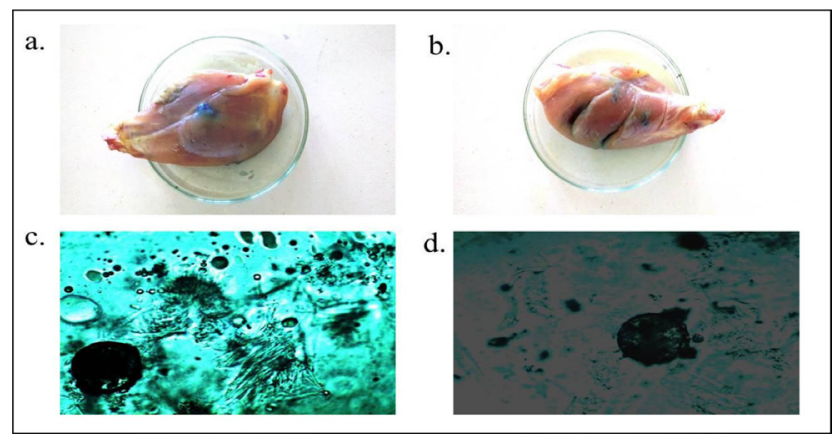

Figure 7: Ex-vivo study of Goserelin Acetate loaded in-situ forming microparticles $(a, b)$ Formation of microparticles in chicken leg tissues and (c, d) Digital microscopy of transverse section of leg tissue after $24 \mathrm{hr}$. were shows microparticles generation.

were shows controlled drug delivery from microparticles up to $24 \mathrm{~h}$ to obtained linear curve with negligible burst effect obeyed the zero order of release. The drug release was observed $95.97 \%, 94.02 \%$ and $97.77 \%$ after 24 days in the batches $\mathrm{A}, \mathrm{B}$ and $\mathrm{C}$ respectively.

From the $\%$ in vitro drug release profile of first 2 days showed in figure that no burst release of drug seen on different batches of formulations because of in ISM system the polymer phase was first emulsified with oil phase prior to administration, which formed a barrier between aqueous medium and polymer solution. The low solubility of drug in oil phase reason the drug to stay in the polymer phase as it were encapsulate within the precipitate polymer. The polymer hardening was depending upon the concentration of surrounded external phase. Globules were close to the surface of emulsion were rapidly solidify as compared to globules were present in depth in emulsion. Therefore, liquidliquid demixing delayed and slow phase inversion in order to several days to weeks, thus result formed homogenous particle surface leads to control the drug release up to long time. Therefore, in situ forming 


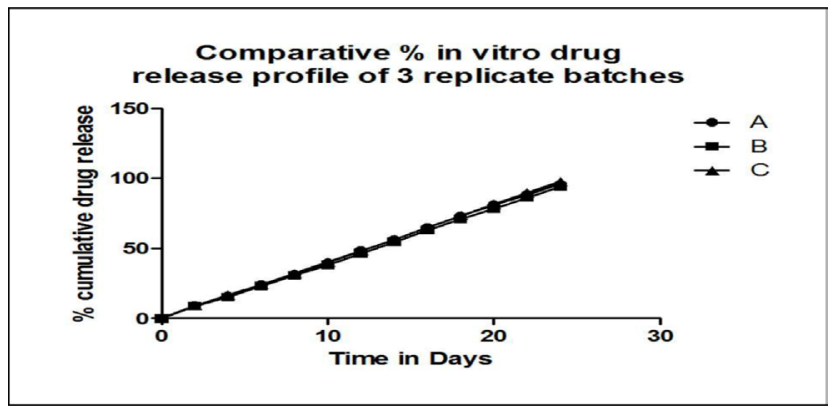

Figure 8: Comparative percentage in vitro cumulative drug release profile of different batches for 24 days.

Table 3: $\mathbf{R}^{2}$ value for drug release kinetic model.

\begin{tabular}{|c|c|c|c|c|}
\hline \multirow{2}{*}{ Kinetic model } & \multicolumn{4}{|c|}{ Formulation code } \\
\hline & \multicolumn{2}{|c|}{ A } & \multirow{2}{*}{$\begin{array}{c}\text { B } \\
0.999\end{array}$} & \multirow{2}{*}{$\begin{array}{c}C \\
0.999\end{array}$} \\
\hline Zero order & $\mathbf{R}^{2}$ & 0.999 & & \\
\hline First order & $\mathbf{R}^{2}$ & 0.847 & 0.870 & 0.786 \\
\hline Higuchi model & $\mathbf{R}^{2}$ & 0.921 & 0.919 & 0.918 \\
\hline Hixson- Crowell model & $\mathbf{R}^{2}$ & 0.939 & 0.946 & 0.915 \\
\hline \multirow{2}{*}{$\begin{array}{c}\text { Korsmeyer- Peppas } \\
\text { model } \\
\mathbf{N}\end{array}$} & $\mathbf{R}^{2}$ & 0.897 & 0.890 & 0.911 \\
\hline & 0.772 & 0.793 & 0.796 & \\
\hline
\end{tabular}

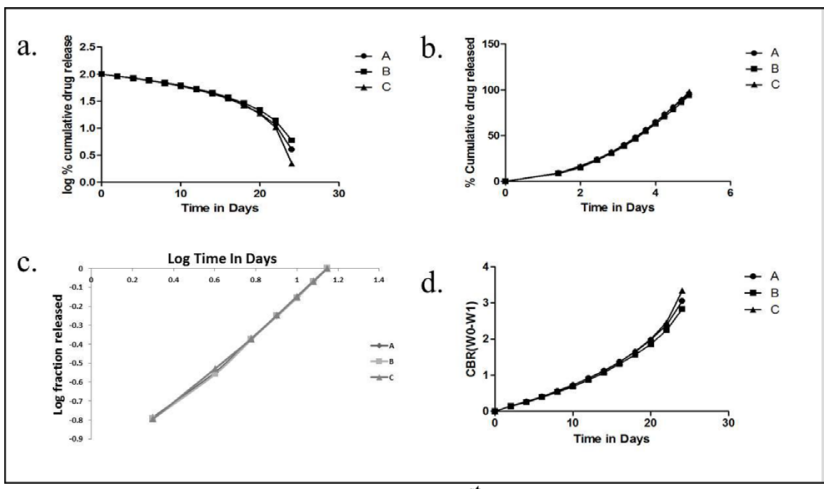

Figure 9: Different kinetic release models, (a) $1^{\text {st }}$ order model, (b) Higuchi model, (c) Korsmeyer-Peppas model and (d) Hisxon-Crowell model.

microparticles have less porous particle surface being another opportunity for the negligibly burst release of drug.

\section{Drug Release kinetic models}

From the results of mathematical model in Table 3 it appears that the formulation follows zero order models as it shows the highest $\mathrm{R}^{2}$ value. The mechanism of diffusion was found to be non- fickian from the $\mathrm{n}$ value as shown in the table. Figure 9. Drug release kinetics, was indicates the integrity of the drug release from the in situ formulations when evaluated by different mathematical models.

\begin{tabular}{|c|c|c|c|c|}
\multicolumn{5}{|c|}{ Table 4: Stability study data of 1 month of optimized } \\
formulation. \\
\hline $\begin{array}{c}\text { Time } \\
\text { (Days) }\end{array}$ & $\begin{array}{c}\text { Drug } \\
\text { content (\%) }\end{array}$ & $\mathbf{p H}$ & Appearance & $\begin{array}{c}\text { Syringe } \\
\text { ability }\end{array}$ \\
\hline 0 & 98.34 & 6.87 & Clear solution & Pass \\
\hline 7 & 98.12 & 6.81 & Clear solution & Pass \\
\hline 14 & 98.10 & 6.78 & Clear solution & Pass \\
\hline 21 & 97.98 & 6.79 & Clear solution & Pass \\
\hline 28 & 97.91 & 6.82 & Clear solution & Pass \\
\hline
\end{tabular}

\begin{tabular}{|c|c|c|c|c|c|c|}
\hline Table 5: Comparison of drug content, pH by ANOVA. \\
\hline Time in days & $\mathbf{0}$ & $\mathbf{7}$ & $\mathbf{1 4}$ & $\mathbf{2 1}$ & $\mathbf{2 8}$ & $\boldsymbol{P}$ - value \\
\hline Drug content (\%) & 98.34 & 98.12 & 98.10 & 97.98 & 97.91 & 1.4607 \\
\hline $\mathrm{pH}$ & 6.87 & 6.81 & 6.78 & 6.79 & 6.82 & 0.184622 \\
\hline
\end{tabular}

\section{Stability Studies}

The stability study was carried out at $4^{\circ} \mathrm{C}$ as PLGA is known to degrade fast to high temperature. The Table 4 showed different parameters were analyzed at different time interval of one week during one month. There was no difference showed in appearance of polymeric solution was able to pass through 18-gauge needle so there was no difference found with syringe ability.

Drug content was found to stable during 1 month of stability study. The data from the Table 4 were analyzed by one way ANOVA. The P-value was found to be more than 0.05 for parameters shown Table 5. So it can be said that there was no significant changes in drug content and $\mathrm{pH}$ of polymer solution during 1 month of stability study. Hereby it can be said that polymeric solution of formulation was found to be stable at $4^{\circ} \mathrm{C}$.

\section{CONCLUSION}

This research study we concluded that formulation of in situ forming microparticles by adjusted the HLB value with selective emulsifier mixture of Span 80 and Tween 80 increased the physical stability of the nonaqueous emulsion. Microparticles were observed under inverted biological microscope until complete precipitation of polymer within the micro-globules, slow rate of diffusion and leaching of DMSO from globules formed spherical, non- porous and dense polymer matrix.

\section{ACKNOWLEDGEMENT}

We are sincerely thankful to Gujarat Council on Science and Technology (GUJCOST/MRP/2015-16/384) for providing Research grant for this project. We are also thankful to Shree Dhanvantary Pharmacy College for providing us Infrastructure facilities and moral 
support to carry out this research work. I sincerely express my deep gratitude to Evonik, Mumbai for providing PLGA as a gift sample.

\section{CONFLICT OF INTEREST}

The authors declare no conflict of interest.

\section{ABBREVIATIONS}

ISM: In situ Microparticle; PLGA: Poly Lactic-Co-Glycolic Acid; DMSO: Dimethyl Sulfoxide; HLB: Hydrophile Lipophile Balance.

\section{REFERENCES}

1. Shankar P, Verma AK, Dixit RK. Prostate cancer: emerging pharmacotherapeutic modalities. Int J Basic Clin Pharmacol. 2013;2(3):247-51.

2. Jerome S, David JS, Naomi A, Peter C, Charles LB, Timothy JW. SingleTherapy Androgen Suppression in Men with Advanced Prostate Cancer: A Systematic Review and Meta-Analysis. Ann Intern Med. 2000;132(7):566-77.

3. Ye M, Kim S, Park K. Issues in long term protein delivery using biodegradable microparticles. Int J Controlled Release. 2010;146(2):241-60.

4. Kempe S, Mader K. In-situ forming implants- an alternative formulation principle for parenteral depot formulation. J Control Release. 2012;161(2):668-79.

5. Kranz $\mathrm{H}$, Bodmeire R. A novel in situ drug delivery system for controlled parenteral drug delivery. Int J Pharm. 2007;332(1-2):107-14.

6. Bodmeier R, Luan X. Influence of the poly (lactide-co-glycolide) type on the leuprolide release from in situ forming micro-particle system. J Control Release. 2006;110(2):226-72.
7. Luan X, Bodmeire R. In situ forming micro-particle system for controlled delivery of leuprolide acetate: Influence of formulation and processing parameters. Eur J Pharm Sci. 2006;27(2-3):143-9.

8. Yapar EA, Inal O, Ozkan Y, Barkara T. Injectable in situ forming microparticle: A novel drug delivery system. Trop J Pharm Res. 2012;11(2):307-18.

9. Giri TK, Choudhary C, Alexander A, Baswaik H, Tripathi DK. Prospects of pharmaceuticals and biopharmaceuticals loaded microparticles prepared by double emulsion technique for controlled delivery. Saudi Pharm J. 2013;21(3):125-41.

10. Nahar K, Gupta N, Gauvin R, Patel B. In vitro, in vivo and ex vivo models for studying particle deposition and drug absorption of inhaled pharmaceuticals. Eur J Pharm Sci. 2013;49(5):805-18.

11. Murakami H, Kobayashi M, Takeuchi H, Kawashima Y. Preparation of PLGA nanoparticles by modified spontaneous emulsification solvent diffusion method. Int J Pharm. 1999;187(2):143-52.

12. Thejaswi N, Srinivas $P$, Mamidi S, Shah S. Preparation and characterization of goserelin acetate loaded microspheres. Int $\mathrm{J}$ Pharm Pharmsci. 2013;5(1):184-9.

13. Bhagwatwar HP, Bapat VR, Chaturvedi NC. Novel in situ forming controlled release micro-carrier delivery system, United States patent. US2003/0049320A1. 2003.

14. Costa P, Lobo JM. Modelling and comparison of dissolution profiles. Eur J Pharm Sci. 2001;13(2):123-33.

15. Darji RV, Patel KR, Patel MR, Patel NM. Formulation and evaluation of tramadol matrix type transdermal patch. Int $\mathrm{J}$ Univers Phar Bio Sci. 2013;2:237-58.

16. Che X, Wang L, Li Q, Liu H. Injectable long-term control-released in situ gels of hydrochloric thiothixene for the treatment of schizophrenia: Preparation, in vitro and in vivo evaluation. Int J Pharm. 2014;469(1):23-30.

17. Mansour HM, Sohn M, Deluca A. Materials for pharmaceutical dosage forms: molecular pharmaceutics and controlled release drug delivery aspects. Int J Mol Sci. 2010;11(9):3298-22.

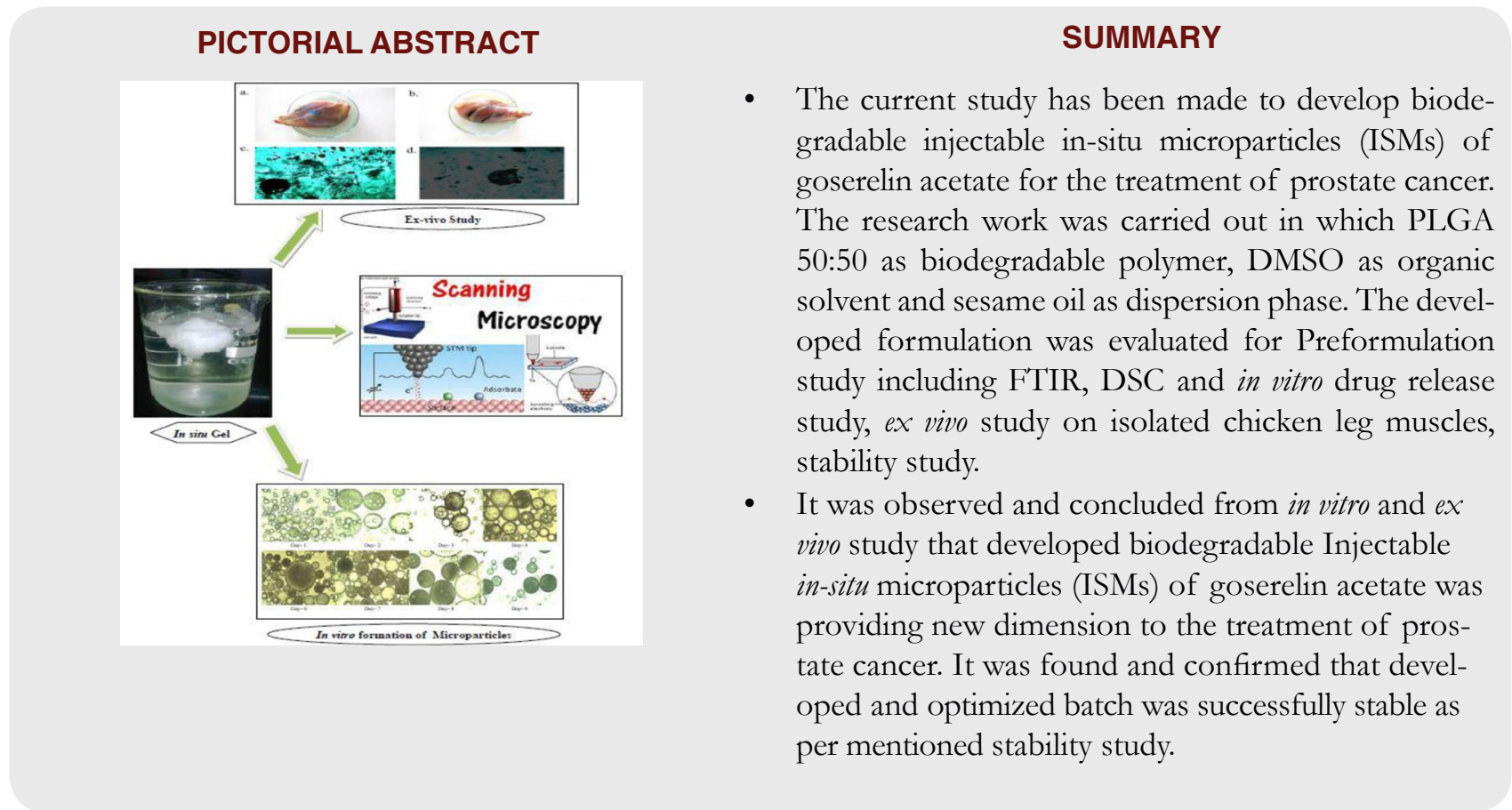




\section{ABOUT AUTHORS}

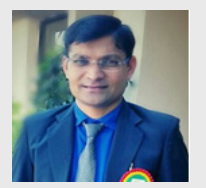

Dr. BhaveshAkbari, Currently working as Professor and Head, Department of Pharmaceutics, Shree Dhanvantary Pharmacy College, Kim, Surat, Gujarat, India. He has 12 years of Teaching and Research experience. He has published more than 35 research and Review papers in reputed peer review National and International journals. He has filed 03 Indian Patents at IPO, Mumbai. He has published 01 International Book as a main Author. He has guided 33 PG and 20 UG students for their research Dissertation. He is reviewer in various National and International peer review journals. He has received more than 7 lakhs research grant from GUJCOST(DST), Gujarat. He has attended 22 National and 06 International Conferences/Seminars. He has attended 03 Faculty Development Program sponsored by AICTE/PCI. He has presented more than 25 research paper at Various Conferences/Seminars. He is life member of APTI, IPA and GSPC.

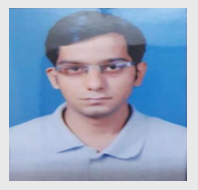

Mr. Rohan Barse, Currently working as Assistant Professor and Head, Department of Quality Assurance, Shree Dhanvantary Pharmacy College, Kim, Surat, Gujarat, India. He has 6 years of Teaching \& Research experience. He has published 5 research articles in reputed peer review National \& International journals. He has filed 03 Indian Patents at IPO, Mumbai. He has published 01 book as a main Author. He has guided 3 PG students for their research Dissertation. He has attended 06 National \& International Conferences/Seminars. He has attended 01 Faculty Development Program sponsored by $\mathrm{PCl}$. He has presented more than 25 research paper at Various Conferences/Seminars.

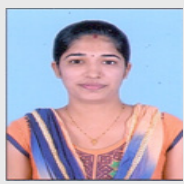

Mrs. Velenti Chauhan, Currently working as an Assistant Professor of Department of Pharmaceutics, Shree Dhanvantary Pharmacy College, Kim, Surat, Gujarat, India. She has 1.5 years of Teaching and Research experience. She has Co-guided 1 PG student for their research Dissertation. She has attended 02 National and 02 International Conferences/Seminars. She has presented 02 research paper at Various Conferences/Seminars.

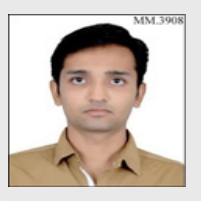

Mr. Vimal Patel, has completed M. Pharm in Pharmaceutics from Shree Dhanvantary Pharmacy College, Kim, Surat, Gujarat, India. He has attended various National and International Conferences Seminars.

Cite this article: Chauhan V, Patel V, Akbari B, Barse R. Development and Evaluation of Biodegradable Polymeric Based Long Acting In situ Forming Microparticles of LHRH Agonist Goserelin Acetate. Indian J of Pharmaceutical Education and Research. 2019;53(2):216-24. 